\title{
Laparoscopic Treatment of Gangrene of Giant Meckel's Diverticulum Secondary to Axial Torsion
}

\author{
Gui-Ae Jeong, M.D., Zisun Kim, M.D. \\ Departments of Surgery, Soonchunhyang University College of Medicine, Bucheon Hospital, Bucheon, Korea
}

\begin{abstract}
Meckel's diverticulum is a common congenital anomaly in the small bowel. Most cases of Meckel's diverticulum are asymptomatic and are found incidentally. We herein report on a case of a 21-yearold male patient who complained of lower abdominal pain and febrile sensation with incidentally diagnosed gangrenous change of Meckel's diverticulum due to axial torsion itself. A 21-year-old man presented to our institution with acute lower abdominal pain. No accurate focus on abdominal pain such as appendicitis or diverticulitis was observed on abdominal ultrasonography and abdominal CT scan. However, the physical examination of the patient revealed the symptom of localized peritonitis with fever. Finally, laparoscopic exploration was performed to determine the cause of acute abdominal pain. During the operation, we found gangrenous change of Meckel's diverticulum with axial torsion itself and laparoscopic Meckel's diverticulectomy was performed. The patient made an uneventful recovery and was discharged on the $6^{\text {th }}$ postoperative day.
\end{abstract}

Keywords: Meckel Diverticulum, Torsion Abnormality, Laparoscopy
Received June 8, 2015

Revised July 13, 2015

Accepted August 24, 2015

Corresponding author

Gui-Ae Jeong

Department of Surgery,

Soonchunhyang University College of Medicine, Bucheon Hospital, 170, Jomaru-ro, Wonmi-gu, Bucheon 14584, Korea Tel: +82-32-621-5066 Fax: +82-32-621-6950

E-mail: gwsdlove@schmc.ac.kr
This is an Open Access article distributed under the terms of the Creative Commons Attribution Non-Commercial License (http:/l creativecommons.org/licenses/by-nc/4.0/) which permits unrestricted non-commercial use, distribution, and reproduction in any medium, provided the original work is properly cited.
Copyright @ 2015 The Journal of Minimally Invasive Surgery. All rights reserved.

\section{INTRODUCTION}

Meckel's diverticulum (MD) is the congenital anomaly of the gastrointestinal tract and results from an incomplete obliteration of the omphalomesenteric duct. ${ }^{1}$ Most of the MD is asymptomatic and the incidence of complication of MD has been reported to be about $4 \%{ }^{2}$ Complicated MD may occur presenting to bleeding, perforation, inflammation, or obstruction. However, the axial torsion itself and gangrenous change of MD is very rare complication. And this condition is difficult to diagnose preoperatively because of its rarity and various clinical features. Herein, we present a case of gangrene of MD with axial torsion treated laparoscopic resection of MD successfully.

\section{CASE REPORT}

A 21-year-old man presented to the Department of Emergency with acute lower abdominal pain. The patient had no nausea, vomiting, melena, or hematochezia. He had no history of any abdominal surgery in the past. On initial examination, his vital signs were stable except to high body temperature up to $37.9^{\circ} \mathrm{C}$. The physical examination revealed the lower abdominal tenderness and rebound tenderness. However his abdominal pain was not severe as his Numeric Rating Scale (NRS) was 3 point. Laboratory examination demonstrated that the white cell count was elevated at 13,230/ $\mu 1$ with a neutrophilia (91.0\%) and C-reactive protein titer was $20.9 \mathrm{mg} / \mathrm{dl}$ (normal range 0 0.5 mg/dl). All other laboratory examinations were within normal limits. Abdominal ultrasonography revealed the no abnormal findings and abdominal 
CT scan suggested the normal appendix and small amount of Ascites (Fig. 1). There was no evidence of acute appendicitis. Although the radiologic examination could not suggest the accurate diagnosis which required the surgical treatment, we decided the laparoscopic exploration because of his severe abdominal tenderness compared to mild abdominal pain, suggesting secondary peritonitis. On the laparoscopic view, we found the severe inflammation of the small bowel on the pelvic cavity and phlegmon formation surrounded to the inflamed small bowel (Fig. 2A). After the dissection of phlegmon, purulent fluid collection with necrotic small bowel was found. Gangrenous Meckel's diverticulum (MD) was observed after tracing the small bowel from the ileocecal valve and the base of MD twisted counterclockwise $\left(360^{\circ}\right)$ along the longitudinal axis (Fig. 2B). This torted and gangrenous MD was located antimesenteric side of ileum approximately distal $100 \mathrm{~cm}$ from the ileocecal valve. The diverticulum was resected using laparoscopic linear stapler at the healthy base of diverticulum without small bowel resection (Fig. 2C, 2D). Also incidental appendectomy was performed. Histologic findings revealed MD with totally hemorrhagic necrosis measuring 12 $\times 2.5 \times 2 \mathrm{~cm}$. The postoperative course was uneventful and the patient was discharge on the postoperative day 6 .
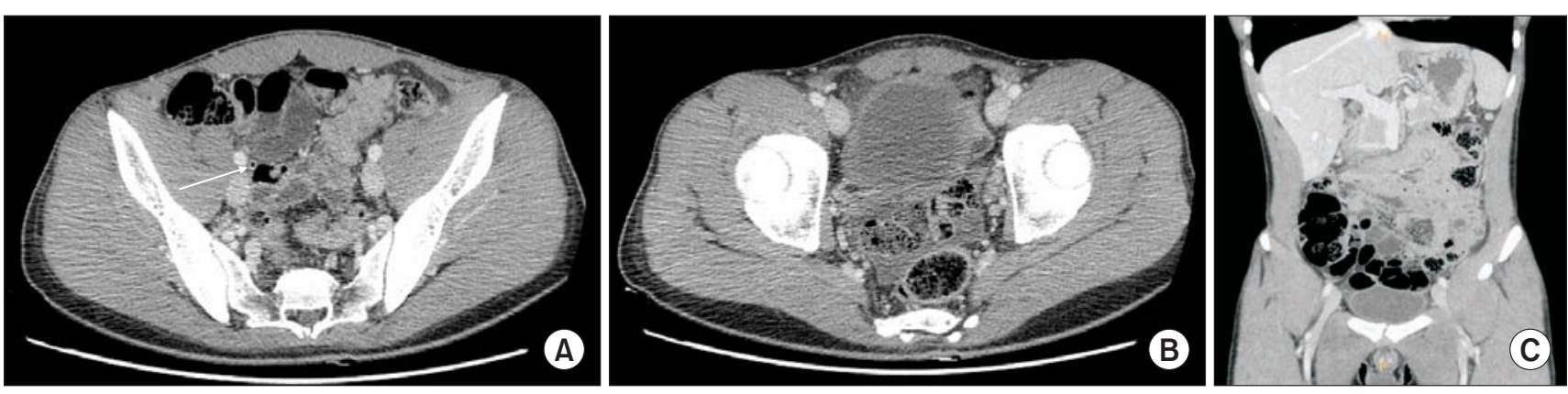

Fig. 1. Preoperative contrast-enhanced abdominal CT scan revealed the only small amount of pelvic ascites and normal appendix. There was no definitive abnormality such as intraabdominal abscess or abnormal extraluminal gas. (A) and (B) Axial image, (C) Coronal reconstruction image.
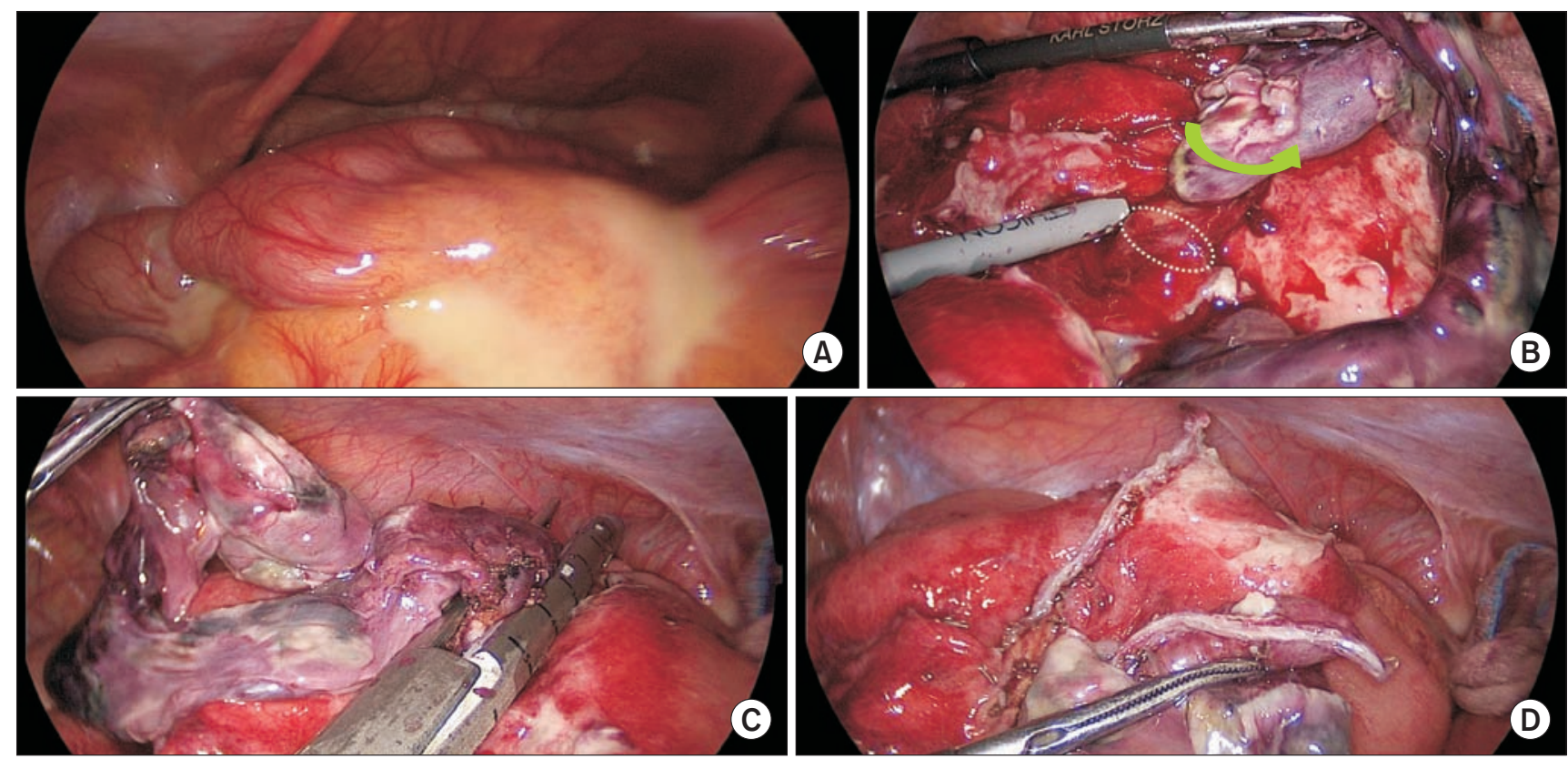

Fig. 2. Intraoperative findings of Meckel's diverticulum torsion. (A) On the laparoscopic view, there was severe inflammation of the small bowel on the pelvic cavity and phlegmon formation surrounded to the inflamed small bowel. (B) Gangrenous Meckel's diverticulum (MD) was observed after tracing the small bowel and the base of $\mathrm{MD}$ (dotted circle) twisted counterclockwise $\left(360^{\circ}\right)$ along the longitudinal axis (arrow). (C) The diverticulum was resected using laparoscopic linear stapler at the healthy base of diverticulum. (D) After the resection of MD, there was no stricture of small bowel. 


\section{DISCUSSION}

Persistent of part or all of the omphalomesenteric duct results in variable abnormalities related to the intestine and abdominal wall. Of these anomalies, the Meckel's diverticulum (MD) is the most common form of the incomplete obliteration of the omphalomesenteric duct. It was reported initially in 1598 by Hildanus and then first named in 1809 by Johann Friedrich Meckel. ${ }^{3}$ This diverticulum is the true diverticulum arises from the antimesenteric border of the small bowel. A Rule of $2 \mathrm{~s}$ is often suggested to this condition in that it is found in about $2 \%$ of the population, is located within 2 feet of the ileocecal valve, is often 2 inches in length, and contains two types of ectopic mucosa (gastric and pancreatic). ${ }^{3}$

Although most of the MD is asymptomatic, complicated MD were reported up to $4 \%$. $^{2}$ The types of complications of MD were various; intestinal obstruction, intussusception, inflammation, hemorrhage, perforation, and so on. ${ }^{1}$ In cases of hemorrhage from MD, up to $90 \%$ of bleeding diverticula contained the heterotopic mucosa (gastric or pancreatic mucosa) and it could be detected before treatment via radionuclide scans ( $99 \mathrm{~m} \mathrm{Tc}-$ pertechnetate). The inflammation of MD (diverticulitis) was hard to diagnose preoperatively and almost cases of Meckel's diverticulitis were diagnosed as acute appendicitis with or without perforation.

Axial torsion itself is very rare presentation of MD and most of all were reported in case report diagnosed incidentally or postoperatively. ${ }^{4-9}$ The patients who were diagnosed axial torsion of MD usually presented preoperatively as intestinal obstruction or right lower quadrant pain mimicking the acute appendicitis. And in these patients, the axial torsion occurred the narrow base of MD and the length of torted MD was very long $(6 \sim 16 \mathrm{~cm})$. In our case, the gangrenous Meckel's diverticulum (MD) was $12 \mathrm{~cm}$ in length and twisted counterclockwise along the longitudinal axis on its relatively narrow base. It was known that increasing the diverticular length with the narrow base of MD was important predisposing factor for all types of complication of MD. ${ }^{5}$

Although our patient had mild lower abdominal pain and there was no evidence of any abnormalities such as appendicitis or intestinal obstruction requiring the surgical treatment, the patient had peritoneal irritation sign suggesting secondary peritonitis and we decided the surgical intervention for accurate diagnosis and definitive treatment.

The decision making for treatment in case of discrepancy between clinical presentation and radiologic findings must be careful and laparoscopic exploration can be helpful to diagnose and treat the patient. Laparoscopic Meckel's diverticulectomy for complicated MD may be very useful and non-invasive treatment even though presence of intraperitoneal abscess or peritonitis like as our case. Some authors emphasized that diagnostic laparoscopy could facilitate the accurate diagnosis atypical abdominal pain and prompt treatment of complicated MD., And also it may be possible to perform Meckel's diverticulectomy by exteriorization of MD through the extension of umbilical incision ${ }^{9}$ or by totally laparoscopic procedure ${ }^{8}$ or by conversion to laparotomy after laparoscopic exploration. Relatively longer MD that is more than twice the length of its diameter tends to possess the ectopic gastric or pancreatic mucosa in its tip rather than the base of MD..$^{10}$ Therefore the Meckel's diverticulectomy for treatment of complicated MD might be feasible if the base of MD was healthy. For these reason as above, we performed the totally laparoscopic Meckel's diverticulectomy despite of its gangrenous change because the base of torted MD was relatively healthy.

If the patient has symptoms of peritonitis despite of obscure radiologic findings, the laparoscopic exploration may be helpful to diagnose and treatment of complicated Meckel's diverticulum undetected preoperatively.

\section{REFERENCES}

1) Yahchouchy EK, Marano AF, Etienne JC, Fingerhut AL. Meckel's diverticulum. J Am Coll Surg 2001;192:658-662.

2) Soltero MJ, Bill AH. The natural history of Meckel's Diverticulum and its relation to incidental removal. A study of 202 cases of diseased Meckel's Diverticulum found in King County, Washington, over a fifteen year period. Am J Surg 1976;132:168-173.

3) Townsend CM Jr., Beauchamp RD, Evers BM, Mattox KL. Sabiston Textbook of Surgery: The Biological Basis of Modern Surgical Practice. 19th ed. Phildelphia: Saunders; 2012.

4) Eser M, Oncel M, Kurt N. Gangrene secondary to axial torsion in a patient with Meckel's diverticulum. Int Surg 2002;87:104-106.

5) Tan YM, Zheng ZX. Recurrent torsion of a giant Meckel's diverticulum. Dig Dis Sci 2005;50:1285-1287.

6) Prasad TR, Chui $\mathrm{CH}$, Jacobsen AS. Laparoscopic resection of an axially torted Meckel's diverticulum in a 13-year-old. J Laparoendosc Adv Surg Tech A 2006;16:425-427.

7) Seth A, Seth J. Axial torsion as a rare and unusual complication of a Meckel's diverticulum: a case report and review of the literature. J Med Case Rep 2011;5:118.

8) Hadeed AA, Azar RR, Azar NN, Benninger B. Meckel's diverticulum complicated by axial torsion and gangrene. J Surg Case Rep 2015; pii: rjv008.

9) Nose S, Okuyama H, Sasaki T, Nishimura M. Torsion of Meckel's Diverticulum in a Child. Case Rep Gastroenterol 2013;7:14-18.

10) Varcoe RL1, Wong SW, Taylor CF, Newstead GL. Diverticulectomy is inadequate treatment for short Meckel's diverticulum with heterotopic mucosa. ANZ J Surg 2004;74:869-872. 